\title{
The effects of kava on alerting and speed of access of information from long-term memory
}

\author{
PAUL N. RUSSELL, DEIRDRE BAKKER, and NIRBHAY N. SINGH \\ University of Canterbury, Christchurch, New Zealand
}

\author{
(K. T. Strongman, Sponsor)
}

\begin{abstract}
The effects of kava, a beverage drunk at social functions in many South Pacific island communities, on alertness (Posner, 1978) and the speed of access of information from long-term memory (Hunt, 1978) was assessed using a variant of Posner's letter-match task. Kava was found to have no effect on the reaction times or errors of two groups of undergraduates who consumed doses thought usual (Experiment 1) and doses much greater (Experiment 2) than those associated with social functions.
\end{abstract}

Kava (kawa or awa), a beverage prepared from the roots of Piper methysticum Forst (piperacaea) and originally consumed in the context of prolonged religious rituals, is now woven into the social customs of many South $\mathrm{Pa}$ cific Island communities (Buckley, Furgiuele, \& O'Hara, 1967; Lemert, 1967). The psychoactive ingredients are pyrone-type compounds that have been observed to have some effect on muscular and motor activity but little effect on more central nervous system functions, although there appear to be no published experimental investigations of its effects on human cognitive processes (Buckley et al., 1967; Hansel, 1968; Kretzschmar, Teschendorf, Loidous, \& Ettenhadieh, 1971; Meyer, 1967).

The present study made a small beginning. Posner's simultaneous letter-match task with variable warning interval (Posner \& Boies, 1971) was employed to assess the effects of kava on alertness (Posner, 1978, chap. 5) and speed of access of information in long-term memory (Hunt, 1978).

\section{EXPERIMENT 1}

\section{Method}

Reaction times (RTs) were obtained from subjects who were instructed to indicate, by depressing a key with an index finger as quickly as they could without making errors, whether a pair of letters displayed on a screen were of the same name or of different names. Three kinds of stimuli were used: those in which the members of a pair were physically identical (PI; e.g., ff, GG); those in which the members were phys-

The data were collected by Deirdre Bakker as part of a master's thesis submitted to the University of Canterbury. The authors thank Colin Burnett for preparing the computer program that controlled the experiment, Ian Douthwaite and Stuart McKenzie for their assistance in preparing programs used in data analysis, and Yadhu Singh of the University of the South Pacific for supplying the kava powder. Purchase of the equipment used in this study was made possible by University of Canterbury Research Equipment Grants 571 970, 572 615, and 573486 made available to Paul N. Russell.

Requests for reprints should be addressed to Paul N. Russell, Department of Psychology, University of Canterbury, Christchurch 1, New Zealand. ically different but of the same name (NI; e.g., fF, Yy); and those in which the members had different names (different; e.g.,. FG, yR). The RT difference NI - PI is commonly taken to provide a measure of the speed with which information in long-term memory is accessed (Hunt, 1978). Posner (1978, chap. 5) used the term alerting to refer to a momentary state in which the central attentional mechanisms interrogate information accruing over input pathways more rapidly, but at the expense of errors. The time course of the buildup of alertness following a warning signal can be traced by varying the interval between the onset of the warning signal and a letter pair.

Two groups, each consisting of 9 caucasian ( 5 male) undergraduates, completed two identical experimental sessions 2-6 days apart. The nokava group consumed no kava prior to either session. The low-dose kava group drank a 250 -ml preparation of $30 \mathrm{~g}$ of kava $30 \mathrm{~min}$ prior to testing on the second occasion. In a process similar to that employed in the South Pacific, $30 \mathrm{~g}$ of kava-root powder from Fiji was soaked in water, twice filtered through a piece of fine muslin cloth, and the residue discarded. The remaining liquid was made up to $250 \mathrm{ml}$ by the addition of water. Knowledge of local methods of preparation and observations of consumption patterns on social occasions suggest the consumed dose to be similar to that frequently occurring in Fiji, at least on social occasions.

An Apple II + computer using software timing (Cavanagh \& Anstis, 1980; Price, 1979) controlled time intervals, presented stimuli, measured RTs, and displayed feedback regarding time and errors to subjects. The warning signal consisted of the simultaneous 60 -msec presentation of the computer "bell" and a center-screen cross. Warning intervals of $60 ; 100,200,500$, and $1,000 \mathrm{msec}$ were used. The letters $(F, f, G, g, R, r, Y, y)$ were constructed in high-resolution graphics from the standard $7 \times 9$ ASCII character font. A letter pair remained in view until a response was made. The stimulus set consisted of $8 \mathrm{PI}$, $8 \mathrm{NI}$, and 16 different pairs. Each pair was presented twice at each warning interval. The order of presentation of the resultant 320 trials was random, except that within a 20-trial block, one PI, one NI and two different pairs were presented at each warning interval. Forty additional trials were presented as practice prior to the stimulus set. A randomly determined interstimulus interval in the range of 2 to $5 \mathrm{sec}$ occurred between the offset of feedback and the onset of the warning for the next trial.

\section{Results and Discussion}

The median of the correct RTs of each subject (RTs outside the range 50 to $3,000 \mathrm{msec}$ were rejected) was found for each kind of letter pair (PI, NI, different) at every warning interval in each session. The medians were treated by a groups $\times$ sessions $\times$ warning interval $\times$ type 
Table 1

Group Mean Reaction Times (in Milliseconds) for Each Kind of Letter Pair at Each Warning Interval

\begin{tabular}{lccccc}
\hline & \multicolumn{5}{c}{ Warning Intervals (in Milliseconds) } \\
\cline { 2 - 5 } & 60 & 100 & 200 & 500 & 1000 \\
\hline PI & 553.7 & 548.2 & 516.3 & 510.7 & 521.2 \\
NI & 709.5 & 710.4 & 666.8 & 626.5 & 650.5 \\
Diff & 702.9 & 665.4 & 677.5 & 655.1 & 658.6 \\
& \multicolumn{5}{c}{ No-Kava Group } \\
PI & 544.0 & 553.7 & 516.7 & 508.2 & 535.0 \\
NI & 699.1 & 682.7 & 635.4 & 617.8 & 636.2 \\
Diff & 682.4 & 662.0 & 661.2 & 642.5 & 643.3 \\
& \multicolumn{5}{c}{ High-Kava Group } \\
PI & 479.6 & 481.1 & 455.5 & 451.7 & 468.2 \\
NI & 631.0 & 591.1 & 565.1 & 561.8 & 570.4 \\
\hline
\end{tabular}

Note-PI = physically identical letter pairs, $\mathrm{NI}=$ name identity pairs, Diff $=$ different letter pairs.

of letter pair analysis of variance. In this analysis, any effects of kava on speed of memory access would be evidenced by the groups $\times$ sessions $\times$ type of letter pair interaction. Similarly, an effect of kava on alerting would be indicated by a significant groups $\times$ sessions $\times$ warning interval effect. No interactions involving groups or sessions approached significance. Errors, almost invariably arising from confusions between NI and different pairs, occurred on $5.3 \%$ of trials. Although the no-kava group made more errors on the second session, the reverse was true of the kava group, indicating that the consumption of kava had no detrimental effect on accuracy of performance.

Group mean RTs, pooled over sessions, are presented in Table 1. In accord with previous findings (Hunt, 1978; Posner, 1978), PI matches were faster than NI and different responses $[F(2,32)=73.92, p<.001]$, and $\mathrm{RT}$ decreased with increasing warning interval, at least up to $500 \mathrm{msec}[F(4,64)=30.47, p<.001]$.

Kava, in the amounts consumed had no discernible effect on the speed with which information was accessed from long-term memory, or on the time course of alerting. Furthermore, the lack of a significant groups $\times$ sessions effect indicates that consumption of kava did not bring about a general slowing of response.

\section{EXPERIMENT 2}

\section{Method}

An additional group of 9 caucasian (5 male) undergraduates completed two sessions of the task employed in Experiment 1, but this group consumed a $500-\mathrm{ml}$ preparation of kava made up to a strength of $1 \mathrm{~g} / \mathrm{kg}$ body weight $1 \mathrm{~h}$ prior to the second experimental session. The no-kava group from Experiment 1 served as the control group.

\section{Results}

Results for the no-kava group and the high-kava group were treated in a manner identical to that of Experiment 1, except that the different data were not included because this condition was peripheral to the aims of Experiment 2. Means for this high-kava group are also presented in Table 1 . As with the low-kava group, no interactions involving groups or sessions approached significance, although the usual differences between NI and PI stimuli and effects of a warning signal were obtained.

\section{GENERAL DISCUSSION}

In two experiments, one employing a dose approximately double that believed to apply in social situations in South Pacific communities, kava produced no effect on the speed of activation of verbal information in long-term memory, or on the rise time or magnitude of the alerting function of a warning signal, although the usual effects of type of letter pair and warning interval were replicated. The null effects of the kava are consistent with a substance in which pyrone-type compounds are the main psychoactive ingredient (Buckley et al., 1967; Hansel, 1968; Kretzschmar et al., 1971; Meyer, 1967). However, since kava is known to affect motor and muscular function (Buckley et al., 1967; Hansel, 1968; Kretzschmar et al., 1971; Meyer, 1967), some generalized slowing of response might have been expected. The very slight and gross movement required to depress the keys in the present experiment may have afforded little opportunity for any muscular and motor impairment to be manifested.

It would be unwise to conclude from this study alone that kava has no effect on cognitive function-obviously, more research is neededbut at this stage it appears preferable to alcohol as a beverage to be consumed on social occasions, at least in terms of its effects on human performance.

\section{REFERENCES}

Buckley, J. P., Furgiuele, A. R., \& O'Hara, M. J. (1967). Pharmacology of kava. In D. H. Efron, B. Holmstedt, \& N. S. Kline (Eds.), Ethnopharmacological search for psychoactive drugs (pp. 141151). Washington, DC: U.S. Department of Health, Education and Welfare.

Cavanagh, P., \& Anstis, S. M. (1980). Visual psychophysics on the Apple II: Getting started. Behavior Research Methods \& Instrumentation, 12, 614-626.

HANSEL, R. (1968). Characterization and physiological activity of some kawa constituents. Pacific Science, 22, 293-313.

Hunt, E. (1978). Mechanics of verbal ability. Psychological Review, 85, 109-130.

Kretzschmar, R., Teschendorf, H. F., Loidous, A., \& EtTenHADIEH, D. (1971). On the sedative action of the kava thizome (Piper methysticum). Acta Pharmacologia, 29, 26.

LEMERT, E. M. (1967). Secular use of kava in Tonga. Journal of Studies on Alcohol, 28, 328-341.

MeYer, H. J. (1967). Pharmacology of kava. In D. H. Efron, B. Holmstedt, \& N. S. Kline (Eds.), Ethnopharmacological search for psychoactive drugs (pp. 133-140). Washington, DC: U.S. Department of Health, Education and Welfare.

Posner, M. I. (1978). Chronometric explorations of mind. Hillsdale, NJ: Erlbaum.

Posner, M. I., \& BoIes, S. J. (1971). Components of attention. Psychological Review, 78, 391-408.

Price, J. M. (1979). Software timing for 6500 series microcomputers. Behavior Research Methods \& Instrumentation, 11, 568-571. 